Research Paper

\title{
Detection of activating and acquired resistant mutation in plasma from EGFR-mutated NSCLC patients by peptide nucleic acid (PNA) clamping-assisted fluorescence melting curve analysis
}

\author{
Chang Gon Kim ${ }^{1,2}$, Hyo Sup Shim ${ }^{3}$, Min Hee Hong ${ }^{1}$, Yoon Jin Cha ${ }^{3}$, Su Jin Heo ${ }^{1}$, \\ Hyung Soon Park ${ }^{1}$, Jee Hung Kim${ }^{1}$, Jin Gu Lee ${ }^{4}$, Chang Young Lee ${ }^{4, *}$, Byoung Chul \\ Cho $^{1,5, *}$ and Hye Ryun Kim ${ }^{1, *}$ \\ ${ }^{1}$ Division of Medical Oncology, Department of Internal Medicine, Yonsei Cancer Center, Seoul, Korea \\ ${ }^{2}$ Graduate School of Medical Science and Engineering, KAIST, Daejeon, Korea \\ ${ }^{3}$ Department of Pathology, Yonsei University College of Medicine, Seoul, Korea \\ ${ }^{4}$ Department of Thoracic and Cardiovascular Surgery, Yonsei University College of Medicine, Seoul, Korea \\ ${ }^{5}$ JE-UK Institute for Cancer Research, JE-UK Co., Ltd., Gumi, Kyungbuk, Korea \\ *These authors contributed equally to this work \\ Correspondence to: Hye Ryun Kim, email: nobelg@yuhs.ac \\ Byoung Chul Cho, email: cbc1971@yuhs.ac \\ Chang Young Lee, email: cyleecs@yuhs.ac
}

Keywords: non-small cell lung cancer, epidermal growth factor receptor mutation, first-generation epidermal growth factor receptor-tyrosine kinase inhibitors, liquid biopsy, peptide nucleic acid clamping-assisted fluorescence melting curve analysis

Received: January 04, 2017 Accepted: April 16, $2017 \quad$ Published: May 10, 2017

Copyright: Kim et al. This is an open-access article distributed under the terms of the Creative Commons Attribution License 3.0 (CC BY $3.0)$, which permits unrestricted use, distribution, and reproduction in any medium, provided the original author and source are credited.

\section{ABSTRACT}

This study was designed to prospectively examine whether peptide nucleic acid clamping-assisted fluorescence melting curve analysis (PANAMutyper ${ }^{\mathrm{TM}}$ ) is feasible for the detection of activating and acquired resistant epidermal growth factor receptor (EGFR) mutation in plasma. Patients with non-small cell lung cancer harboring activating EGFR mutations who were scheduled to undergo EGFR-tyrosine kinase inhibitors (EGFR-TKIs) were enrolled between September 2011 and March 2015. A total of 102 patients with EGFR-mutated lung cancer were enrolled, 53 had available plasma samples at disease progression, and 28 underwent serial plasma sampling during EGFR-TKI treatment. EGFR-TKI-sensitizing and T790M mutations were detected in the plasma of $68.6 \%(70 / 102)$ at baseline and $30.2 \%(16 / 53)$ at disease progression, respectively. The concordance rates for matched tissue and plasma samples were $\mathbf{8 0 . 4 \%}$ and $\mathbf{9 0 . 2 \%}$ for E19del and L858R mutations at baseline and $56.3 \%$ for T790M mutation at disease progression. The sustained presence of plasma EGFR mutations four weeks after EGFR-TKI predicted a poor objective response rate

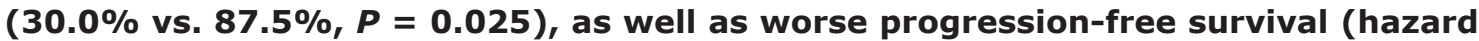
ratio [HR], 4.381) and overall survival (HR, 5.475). Longitudinal analysis could detect T790M mutations earlier than disease progression based on imaging study (median time from appearance of T790M in plasma samples to progression at imaging scan, 103 days). In conclusion, PANAMutyper ${ }^{\mathrm{TM}}$ is reliable for detecting activating and acquired resistant EGFR mutation in plasma, and predicts responses to EGFR-TKI via longitudinal monitoring of EGFR mutation during treatment. 


\section{INTRODUCTION}

Activating epidermal growth factor receptor $(E G F R)$ mutations are predictive biomarkers for response to EGFR-tyrosine kinase inhibitors (EGFR-TKIs; e.g., erlotinib, gefitinib or afatinib) and EGFR-TKIs are the standard first-line therapy for non-small cell lung cancer (NSCLC) with activating EGFR mutations [1-3]. Randomized phase III studies have consistently demonstrated that first-line EGFR-TKI therapy improves progression-free survival (PFS) compared with standard cytotoxic chemotherapy in EGFR mutated lung cancer patients [2-4]. However, most patients treated with EGFR-TKI ultimately develop disease progression due to acquired resistance via multiple mechanisms [5-7]. Of these mechanisms, EGFR T790M mutation accounts for more than $50 \%$ of the acquired resistance [8]. Thirdgeneration EGFR-TKIs have shown promising activity against EGFR T790M mutation-positive NSCLC and recently osimertinib was approved by the US Food and Drug Administration [9]. Therefore, in the era of third generation EGFR-TKI, the detection of EGFR T790M mutation in repeated biopsies at the time of EGFR-TKI failure is indispensable to improving survival outcomes in EGFR mutated patients.

Analysis of EGFR mutations in tumor tissue is not always possible due to the invasive nature of biopsies, inaccessibility of tumor location, or low quantity and quality of the tissue samples $[10,11]$. Moreover, singlesite biopsy cannot provide a representative profile of the overall resistance mechanisms for patients with multiple metastatic sites with heterogeneous characteristics [12]. In reality, a monitoring of mutation dynamics during EGFRTKI through repetitive biopsies is not suitable. Detection of circulating free tumor DNA (ctDNA) in plasma has been considered as a feasible method for diagnosis, prediction of treatment efficacy, and monitoring of recurrence or disease burden in various solid tumors in recent years [13-15]. In meta-analyses, ctDNA has proven to be a highly specific and effective biomarker for the detection of activating EGFR mutation in NSCLC [16, 17]. The T790M mutation was also successfully detected by liquid biopsy through analysis of blood samples $[18,19]$. Compared to tumor tissue biopsy, liquid biopsy for detecting ctDNA is safer because of its non-invasive nature and more feasible for monitoring tumor dynamics as it is representative of multiple tumor sites [20].

Peptide nucleic acids (PNA) are synthetic polymers that bind tightly to a complementary sequence in DNA $[7,21]$. Despite its lack of ability to detect new mutations, PNA-mediated polymerase chain reaction (PCR) clamping assay has advantages of sensitivity, simplicity, and speed for detecting previously known mutations and thus, real-time PCR with PNA has been widely used to detect EGFR mutation. Recently, the Korean Food and Drug Administration approved the PNA Clamp ${ }^{\mathrm{TM}} E G F R$
Mutation Detection kit (PANAGENE Inc., Daejeon, Korea) as a standard screening method for EGFR mutation in lung cancer patients [21,22]. To increase the sensitivity of the PNA clamp method in order to detect even in plasma ctDNA, PNA clamping-assisted fluorescence melting curve analysis (PANAMutyper ${ }^{\mathrm{TM}}$ EGFR kit) was newly developed using a fluorescence melting curve in addition to PNA clamping.

In this study, we prospectively evaluated whether PNA clamping-assisted fluorescence melting curve analysis (PANAMutyper ${ }^{\mathrm{TM}}$ ) can accurately detect activating and acquired resistance EGFR mutations in plasma ctDNA derived from NSCLC patients. Additionally, we aimed to explore dynamic changes in EGFR mutation profiles and the appearance of acquired resistance during EGFR-TKI in EGFR mutated lung cancer patients.

\section{RESULTS}

\section{Patient characteristics and treatment outcomes for EGFR-TKI}

A total of 102 patients with NSCLC harboring activating EGFR mutations were enrolled in this prospective trial of first-generation EGFR-TKI between September 2011 and March 2015 at Yonsei Cancer Center in Korea (Figure 1). Baseline examination of EGFR mutations was performed in 102 patients using matched tumor tissues and plasma samples (Table 1 ). The majority were female $(62 / 102,60.8 \%)$, never smokers $(71 / 102$, $69.6 \%$ ) with extra-thoracic metastatic disease (M1b) $(71 / 102,69.6 \%)$ who received gefitinib $(81 / 102,79.4 \%)$ as the first-line treatment $(72 / 102,70.6 \%)$. The most common mutation identified was E19del (57/102, 55.9\%) and T790M was not detected in any patients at baseline. Objective responses were observed in 64 patients $(62.8 \%)$, including a complete response in one patient $(1 / 102$, $1.0 \%$ ) and a partial response in over half of the patients (63/102, 61.8\%). The median PFS was 13.6 months $(95 \%$ confidence interval $[\mathrm{CI}], 11.6-15.6$ months) and the median overall survival (OS) was 28.6 months $(95 \% \mathrm{CI}$, 12.2-45.0 months). During a median follow-up period of 36.4 months (95\% CI, 31.8-41.1 months), disease progression and death events occurred in $67(65.7 \%)$ and $40(39.2 \%)$ patients, respectively. Dynamic changes in EGFR mutations were analyzed in 28 patients using serial sampling (Supplementary Table 1). At the time of disease progression, 53 blood samples were available, including 16 paired tissue biopsies and blood samples. All causes of death were related to disease progression.

\section{Performance of the platform}

EGFR E19del or L858R mutations were detected in baseline plasma samples prior to treatment in $68.6 \%$ (70/102) of the patients (Table 2). Sensitivity of M1b 
disease was higher than that of M0/M1a disease $(83.1 \%$ vs. $35.5 \%, P<0.001)$. Likewise, median copy numbers of activating EGFR mutation were higher in M1b than in M0/M1a disease (1422.7 copies/mL vs. 431.5 copies $/ \mathrm{mL}$, $P<0.001)$. Concordance rate, sensitivity, and negative predictive value (NPV) between plasma ctDNA and matched tissue were $80.4 \%(80 / 102), 61.8 \%(35 / 57)$, and $67.2 \%(45 / 67)$ for E19del and 90.2\% (92/102), 77.8\% $(35 / 45)$, and $85.1 \%(57 / 67)$ for L858R. E19del mutations were not detected in plasma from patients with L858R mutations and vice versa, yielding a specificity and positive predictive value (PPV) of $100 \%$ for both subtypes of $E G F R$ mutation.

\section{Monitoring of acquired resistance during serial sampling and at disease progression}

A decrease in copy numbers of activating plasma EGFR mutation (E19del or L858R) was seen in $94.4 \%$ of the patients $(17 / 18)$ four weeks after administration of EGFR-TKI, except one patient who progressed within 81 days and revealed detectable plasma T790M at 28 days after treatment (Figure 2). Genomic profiling of tumor tissue from this non-responder by next-generation sequencing revealed mutations in TP53, as well as STK11, which is known to be associated with de novo resistance to EGFR-TKI [23]. Negative conversion of detectable plasma EGFR mutation was seen in $44.4 \%$ of the patients (8/18), and the median rates of decrease in copy numbers was $67.9 \%$ (range, $11.3 \%-100.0 \%$ ). Re-emergence or increasing copy numbers of activating $E G F R$ mutation in plasma was also observed before objective disease progression based on imaging scans according to Response Evaluation Criteria in Solid Tumors (RECIST) 1.1 guidelines. Emergence of acquired resistance (T790M) was always associated with disease progression which was later evaluated based on imaging scan. Median time from appearance of T790M in plasma samples to progression at imaging scan was 103 days (range, 0-169 days).

Among the 67 patients who experienced disease progression after EGFR-TKI treatment, 53 patients had blood plasma samples available at the time of disease progression (Table 3). The prevalence of T790M mutation in plasma was $30.2 \%(16 / 53)$. Comparison between matched tumor tissues by repeated biopsy and plasma at disease progression was performed in 16 patients (Table 4 ). The prevalence of the T790M mutation was $37.5 \%$ (6/16) for tissue samples and 31.3\% (5/16) for plasma samples. The concordance rate of T790M mutations between tissue and plasma samples was 56.3\% (9/16). Seven cases with discrepancies in T790M mutations included three patients who were positive for the T790M mutation in plasma but negative in tissue samples and four patients who showed the reverse. In examination of both tissue and plasma samples, resistance mechanisms to EGFR-TKIs were driven by secondary T790M mutations (9 patients), c-MET amplification by fluorescent in situ hybridization (1 patient), small cell transformation (1 patient), epithelial-to-mesenchymal transition by histologic analysis (1 patient), and unknown causes (4 patients).

Prognostic and predictive value of ctDNA from blood plasma samples. Median PFS was 11.9 months for patients with detectable plasma $E G F R$ mutations before treatment versus 21.4 months for those without detectable mutations (hazard ratio [HR], 2.964; 95\% CI, 1.624-5.409; $P<0.001$; Figure 3A) and median OS was 18.8 versus 37.6 months, respectively (HR, 2.790; 95\% CI, 1.274-6.110; $P=0.007$; Figure 3B). Objective response rates were not significantly different between the two groups. In analysis adjusted for other demographic and clinicopathologic variables, detectable plasma EGFR mutation before EGFR-TKI

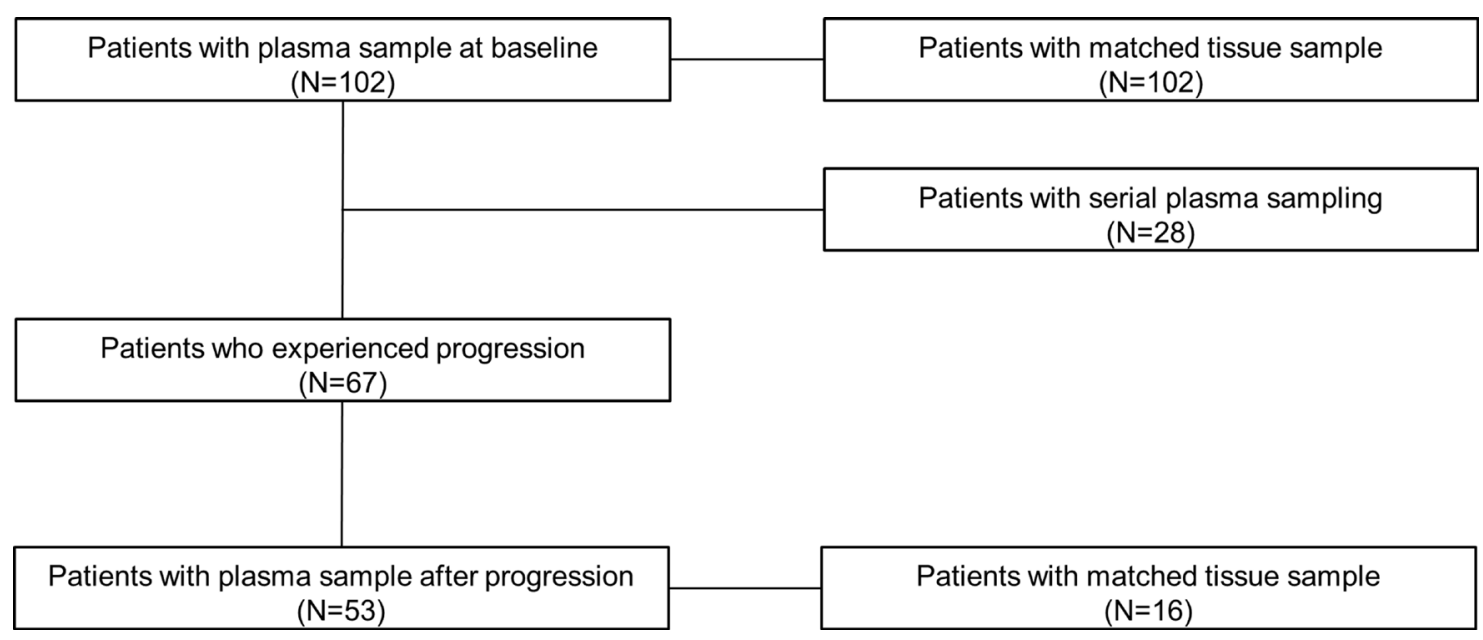

Figure 1: Patients with available tissue or plasma samples before administration of EGFR-TKI, during course of treatment, and after progression. 
Table 1: Baseline characteristics and treatment outcomes of patients $(N=102)$

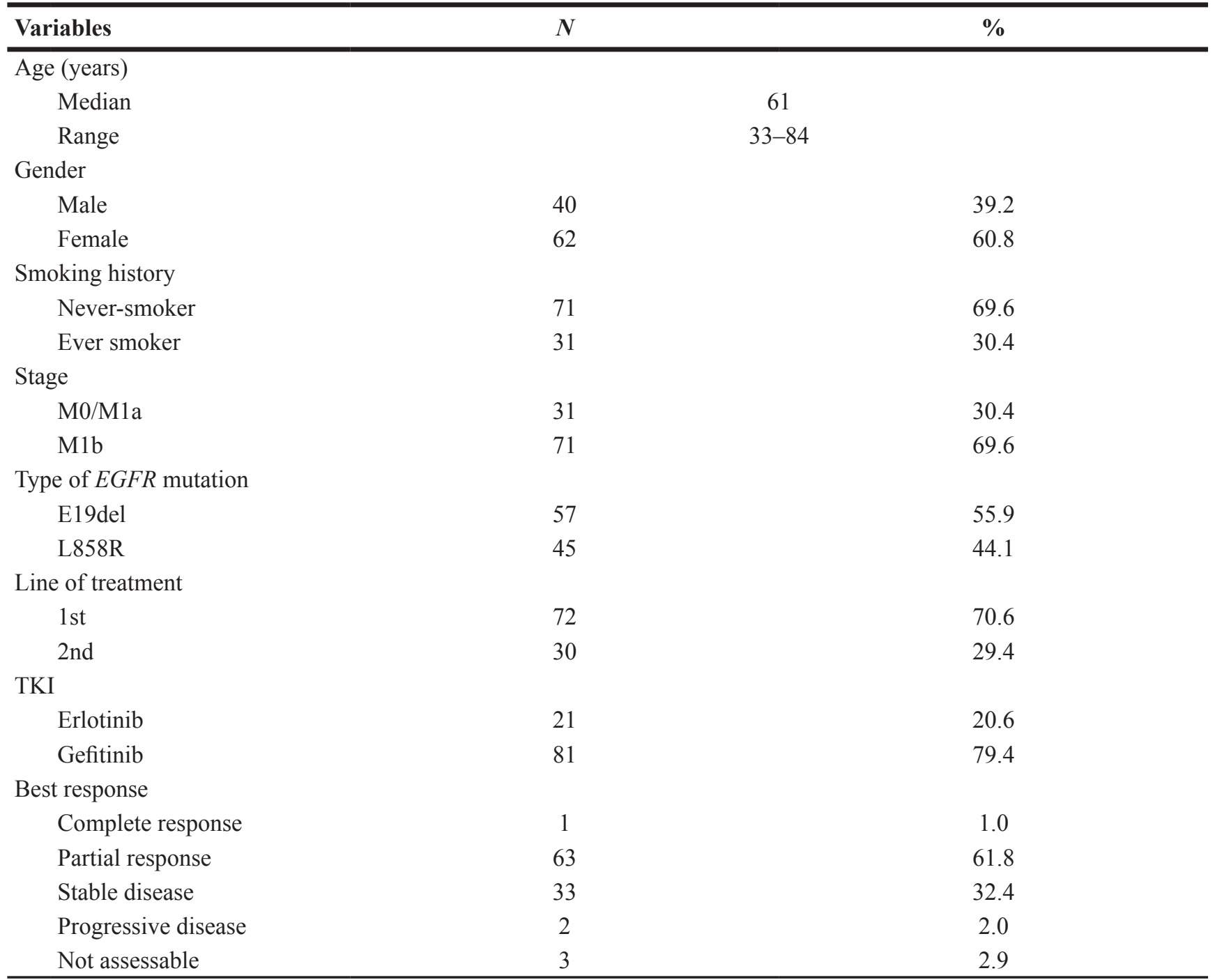

Abbreviations: E19del, exon 19 deletion; EGFR, epidermal growth factor receptor; TKI, tyrosine kinase inhibitor.

Table 2: Comparison between plasma and tissue samples at baseline

\begin{tabular}{lcccc}
\hline & & \multicolumn{3}{c}{ Tissue EGFR mutation } \\
\hline & & E19del & L858R & Total patients \\
\hline \multirow{3}{*}{ ctDNA EGFR mutation } & E19del & 35 & 0 & 35 \\
& L858R & 0 & 35 & 35 \\
& Wild & 22 & 10 & 32 \\
& Total patients & 57 & 45 & 102 \\
\hline
\end{tabular}

Abbreviations: ctDNA, circulating free tumor DNA; E19del, exon 19 deletion; $E G F R$, epidermal growth factor receptor.

was independently associated with worse PFS (HR, 2.694; 95\% CI, 1.416-5.125) and OS (HR, 2.436; 95\% CI, 1.040-5.704), respectively (Table 5). Of the 28 patients who underwent serial plasma sampling, 18 patients $(64.3 \%)$ had detectable EGFR mutations before EGFR-TKI treatment. Moreover, the presence of $E G F R$ mutation after treatment might predict poor prognosis of these patients. Median PFS was 2.7 months for patients with detectable plasma $E G F R$ mutation, even after four weeks of treatment versus 14.1 months for patients without detectable mutations (HR, 4.381; 95\% CI, 1.34014.316; $P=0.016$; Figure 3C), whereas median OS was 18.6 months versus not reached, respectively (HR, 5.475; 95\% CI, 1.425-21.035; $P=0.020$; Figure 3D). Objective response rates after four weeks of treatment were $30.0 \%$ for patients with detectable plasma $E G F R$ mutation and $87.5 \%$ for patients without detectable mutation $P=0.025)$. 
In the case of a 56-year-old female who developed acquired resistance after 9 months' treatment with erlotinib (Figure 4), a plasma sample obtained at disease progression revealed both EGFR E19del and T790M mutations within 48 hours after sampling. A confirmatory lung biopsy was also performed, which revealed only an EGFR E19del mutation 23 days after the procedure. Treatment with a third-generation TKI, HM61713, was subsequently initiated and the patient exhibited a partial response to therapy, which continues to be maintained. The benefits of liquid biopsy including delicate reflection of tumor heterogeneity as well as fast turn-around time can be seen in this case.

\section{DISCUSSION}

This is the first prospective study demonstrating the feasibility of PNA clamping-assisted fluorescence melting curve analysis (PANAMutyper ${ }^{\mathrm{TM}}$ ) of plasma ctDNA derived from NSCLC patients with activating and acquired resistant EGFR mutations. The overall sensitivity and specificity of this platform were $68.6 \%$ and $100 \%$ at baseline, respectively. Longitudinal plasma analysis was found to detect acquired resistance earlier than that of tumor tissue biopsies, and demonstrated that the prevalence of activating and resistant mutations increased over time before progression. Presence of EGFR mutations in plasma prior to EGFR-TKI treatment was associated with impaired survival outcomes. In most patients, DNA copy numbers of activating EGFR mutation decreased in plasma within four weeks after EGFR-TKI. Interestingly, the presence of detectable plasma EGFR mutation four weeks after EGFR-TKI was associated with lower objective response rates and shorter PFS and OS than the absence of mutation.

Recent studies suggest that EGFR mutation analysis with ctDNA through liquid biopsy can be an alternative detection method for patients who cannot receive invasive procedures for tissue analysis [19, 24]. High specificity was observed consistently in several different platforms, although false-negative results are still an important issue regarding the diagnostic value of blood-based analysis in clinical practice. Kim et al. reported that the overall sensitivity of EGFR mutations in ctDNA was $17.1 \%$
A
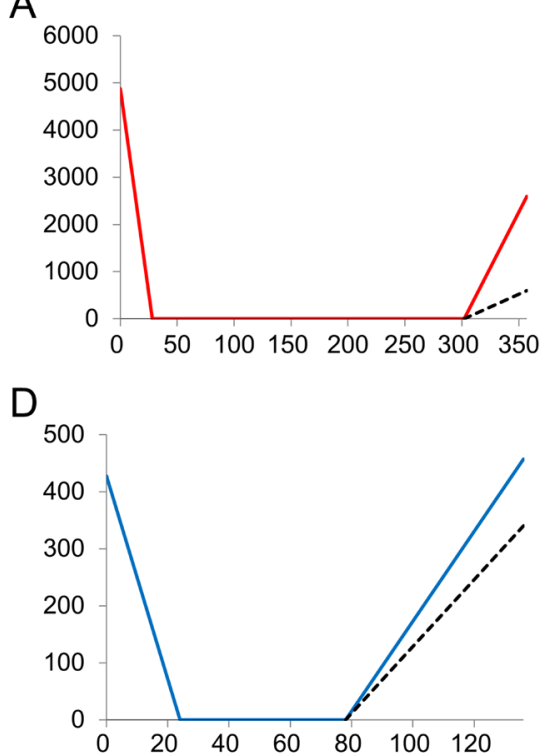

G

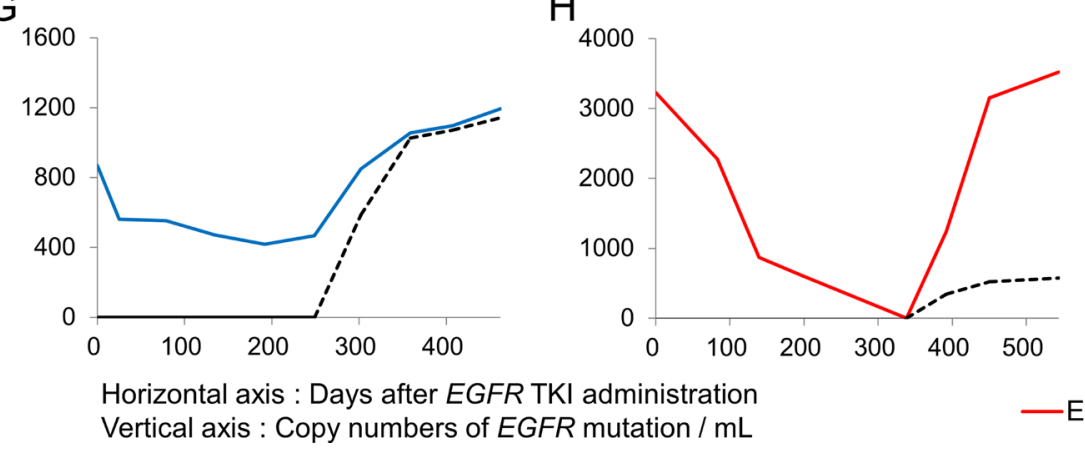

B

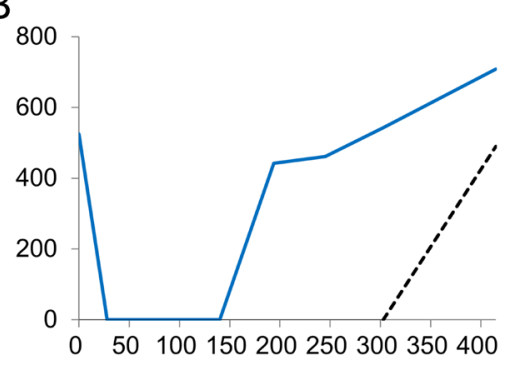

E

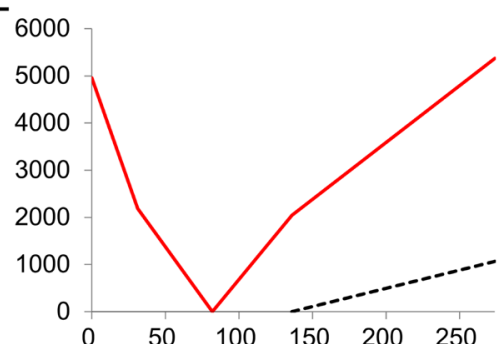

$\mathrm{H}$

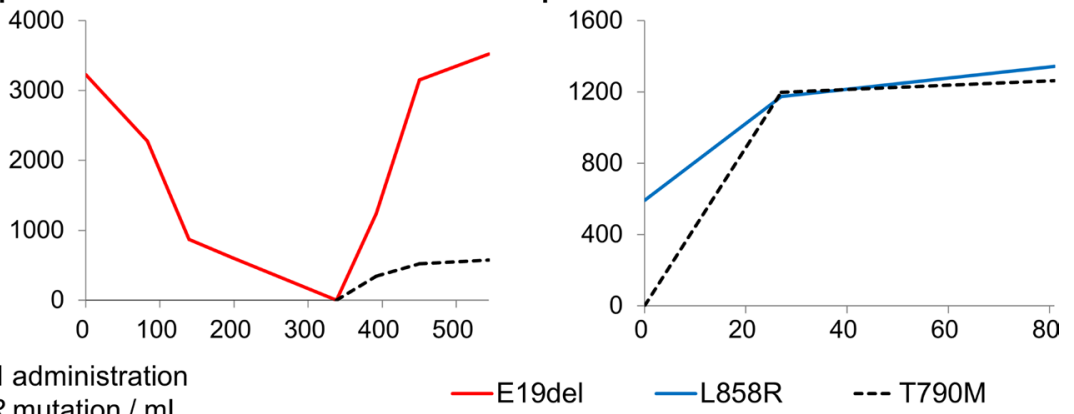

C

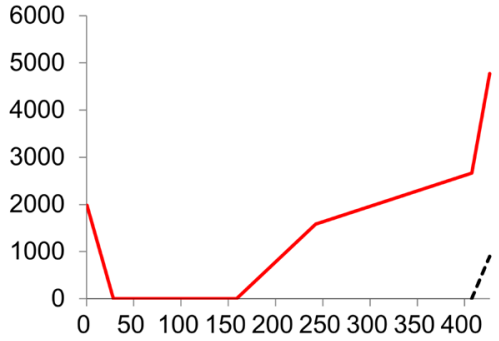

$\mathrm{F}$

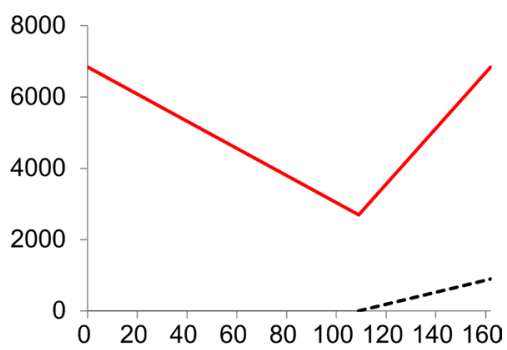

1

1600

Figure 2: Representatives for longitudinal monitoring of activating and resistant EGFR mutations in ctDNA. Each graph $(\mathbf{A}-\mathbf{E})$ represents each patient. 
Table 3: Subtypes of ctDNA EGFR mutation at disease progression $(N=53)$

\begin{tabular}{ccc}
\hline ctDNA $\boldsymbol{E G F R}$ mutation & $\boldsymbol{N}$ & $\mathbf{\%}$ \\
\hline E19del & 8 & 15.1 \\
E19del, T790M & 9 & 17.0 \\
L858R & 9 & 17.0 \\
L858R, T790M & 6 & 11.3 \\
T790M & 1 & 1.9 \\
Wild & 20 & 37.7 \\
\hline
\end{tabular}

Abbreviations: ctDNA, circulating free tumor DNA; E19del, exon 19 deletion; EGFR, epidermal growth factor receptor.

Table 4: Comparison between plasma and tissue samples at disease progression

\begin{tabular}{cccccccc}
\hline \multirow{2}{*}{ E19del } & \multicolumn{5}{c}{ Tissue EGFR mutation } \\
\cline { 3 - 7 } & E19del & 1 & 1 & 0 & 0 & 0 & 2 \\
& E19del,T790M & 2 & 1 & 0 & 0 & 0 & 3 \\
ctDNA $E$ E GFR & L858R & 0 & 0 & 1 & 2 & 0 & 3 \\
mutation & L858R,T790M & 0 & 0 & 1 & 1 & 0 & 2 \\
& Wild & 5 & 0 & 0 & 0 & 1 & 6 \\
& Total patients & 8 & 2 & 2 & 3 & 1 & 16 \\
\hline
\end{tabular}

Abbreviations: ctDNA, circulating free tumor DNA; E19del, exon 19 deletion; EGFR, epidermal growth factor receptor.
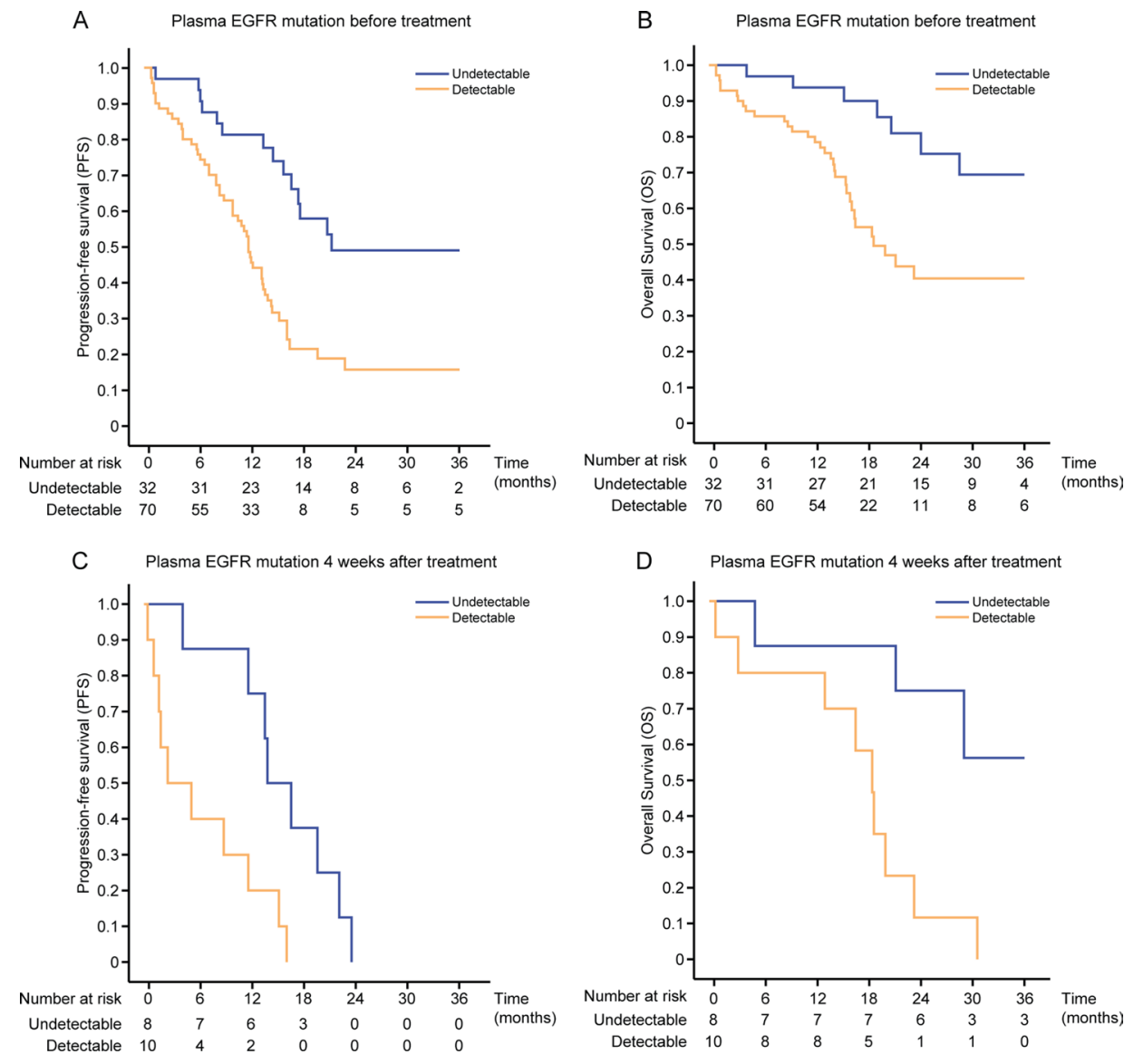

Figure 3: Kaplan-Meier survival estimates for patients according to plasma EGFR mutation. PFS (A) and OS (B) by ctDNA status at baseline. PFS (C) and OS (D) by ctDNA status four weeks after treatment. 
Table 5: Multivariate analysis of prognostic factors with progression-free survival and overall survival

\begin{tabular}{|c|c|c|c|c|c|}
\hline & & \multicolumn{2}{|c|}{ Progression-free survival } & \multicolumn{2}{|c|}{ Overall survival } \\
\hline & & HR (95\% CI) & $P$ value & HR (95\% CI) & $P$ value \\
\hline \multirow[t]{3}{*}{ Gender } & & & 0.239 & & 0.237 \\
\hline & Female & Ref & & Ref & \\
\hline & Male & $0.580(0.234-1.435)$ & & $0.444(0.116-1.706)$ & \\
\hline \multirow[t]{3}{*}{ Smoking history } & & & 0.123 & & 0.271 \\
\hline & Never-smoker & Ref & & Ref & \\
\hline & Ever smoker & $2.139(0.813-5.629)$ & & $2.230(0.534-9.312)$ & \\
\hline \multirow[t]{3}{*}{ Stage } & & & 0.248 & & 0.410 \\
\hline & M0/M1a & Ref & & Ref & \\
\hline & M1b & $1.502(0.753-2.994)$ & & $1.466(0.590-3.643)$ & \\
\hline \multirow[t]{3}{*}{ Type of EGFR mutation } & & & 0.983 & & 0.100 \\
\hline & E19del & Ref & & Ref & \\
\hline & L858R & $0.995(0.598-1.654)$ & & $1.981(0.877-4.476)$ & \\
\hline \multirow[t]{3}{*}{ Line of treatment } & & & 0.302 & & 0.099 \\
\hline & $1 \mathrm{st}$ & Ref & & Ref & \\
\hline & 2nd & $1.321(0.778-2.243)$ & & $1.798(0.896-3.606)$ & \\
\hline \multirow[t]{3}{*}{ TKI } & & & 0.803 & & 0.736 \\
\hline & Gefitinib & Ref & & Ref & \\
\hline & Erlotinib & $1.087(0.566-2.086)$ & & $1.149(0.512-2.581)$ & \\
\hline \multirow[t]{3}{*}{ Presence of pretreatment ctDNA } & & & 0.003 & & 0.040 \\
\hline & No & Ref & & Ref & \\
\hline & Yes & $2.694(1.416-5.125)$ & & $2.436(1.040-5.704)$ & \\
\hline
\end{tabular}

Abbreviations: CI, confidence interval; ctDNA, circulating free tumor DNA; E19del, exon 19 deletion; HR, hazard ratio; Ref, referent; TKI, tyrosine kinase inhibitor.

with PNA-mediated PCR clamping [25]. Similarly, the sensitivity of PNA PCR clamping was low at $22.2 \%(4 / 18)$ in our independent analysis (Supplementary Table 2). On the other hand, by incorporating melting curve analysis to PNA-mediated PCR clamping method, the sensitivity of this platform (PANAMutyper ${ }^{\mathrm{TM}}$ ) increased up to nearly $70 \%$, similar to previous studies conducted by Han et al [26]. This result was comparable to previous studies using the non-digital amplification refractory mutation system (ARMS) assay [27], allele-specific PCR assay [28], next generation sequencing (NGS) [29], and droplet digital PCR (ddPCR) assay [30]. In comparison with other methods, PANAMutyper ${ }^{\mathrm{TM}}$ can be performed simply with real-time PCR and finished in a brief time [7]. Furthermore, it can simultaneously detect multiple mutations while maintaining high sensitivity and specificity [31].

Although EGFR-TKI prolonged survival outcome of patients with activating EGFR mutation, this benefit was not distributed equally among patients $[1,3]$. Hence, plasma-based EGFR mutation analysis has been used to monitor responses to EGFR-TKI in previous studies. Mok et al. reported an association of negative conversion of EGFR mutation of ctDNA 12 weeks after treatment along with prolonged PFS and OS [28]. Lee et al. also showed that detectable EGFR mutation in plasma during the course of treatment was associated with impaired outcomes [30]. In line with these previous studies, the predictive value of plasma $E G F R$ mutation after treatment was proven in the present study. In addition to confirming the correlation of PFS and OS with dynamic changes in EGFR mutation status, we also demonstrated that radiologic response according to RECIST criteria was correlated with posttreatment plasma EGFR mutation status. We evaluated the predictive value of an early response reflected by ctDNA at four weeks after treatment, which is earlier than other previous studies $[28,32]$. Considering that outcomes for patients who continued to have detectable plasma $E G F R$ mutation four weeks after treatment were relatively poor, assessment of plasma $E G F R$ mutation status four weeks after treatment can help in timely discrimination of patients who may benefit from continuing EGFR-TKI.

$\mathrm{T} 790 \mathrm{M}$ is the most common mutation associated with acquired resistance to first-generation EGFRTKIs [8]. The development of third-generation TKIs has substantially benefitted patients with acquired resistance to erlotinib or gefitinib $[9,19]$. Because of the limitation of 
repeated biopsies, several studies have evaluated acquired resistance using non-invasive blood-based analyses $[15,24]$. In the present study, the T790M mutation was found in 16 of 53 patients $(30.2 \%)$, and was detectable as early as six months before objective disease progression. The relative proportion of $\mathrm{T} 790 \mathrm{M}$ mutations increased after the first appearance of such acquired resistance, and all patients with detectable T790M in serial plasma samples eventually experienced disease progression.

When we compared EGFR mutation results of tumor tissues and plasma samples at disease progression, $18.8 \%$ of patients $(3 / 16)$ had detectable T790M in plasma that was not detected via tissue biopsy. This discrepancy could result from the heterogeneous nature of metastatic tumor deposits $[33,34]$. The concordance rate between plasma and tissue for E19del or L858R before EGFR-TKI was higher than that for T790M at disease progression (80.4\% and $90.2 \%$, respectively, vs. $56.3 \%$ ). Therefore, confounding results of repeat biopsy can be supplemented by non-invasive blood-based methods. Studies focusing on the clinical relevance of early detection of resistant mutations in ctDNA or discrepancy of T790M between tumor tissue and plasma samples are underway using ARMS and ddPCR methods (NCT02418234).

Unfortunately, the predictive role of T790M in plasma could not be fully assessed in this study, because of the small number of patients who underwent plasma sampling at disease progression or received subsequent treatment with the third-generation TKI. In addition, repeated tumor biopsy after disease progression was performed in only a small number of patients $(16 / 67$, $23.9 \%$ ), mainly because of clinical deterioration.

In conclusion, PNA clamping-assisted fluorescence melting curve analysis (PANAMutyper ${ }^{\mathrm{TM}}$ ) in plasma samples is a feasible and effective method for diagnosis of activating mutation, prediction of treatment response, and monitoring of acquired resistance during EGFR-TKI treatment. Larger studies on the clinical relevance of T790M genotyping based on this platform are warranted to confirm our results. Ultimately, prospective clinical trials exploring the correlation with response to third-generation EGFR-TKI therapy could help validate the usefulness of this platform for T790M genotyping in clinical practice.

\section{MATERIALS AND METHODS}

\section{Study design}

This study was an exploratory trial to evaluate the performance of a newly developed platform (PANAMutyper $^{\mathrm{TM}}$ ) for detecting activating and acquired resistant $E G F R$ mutation in plasma from NSCLC patients harboring EGFR mutation during EGFR-TKI. Patients with NSCLC harboring activating EGFR mutations were

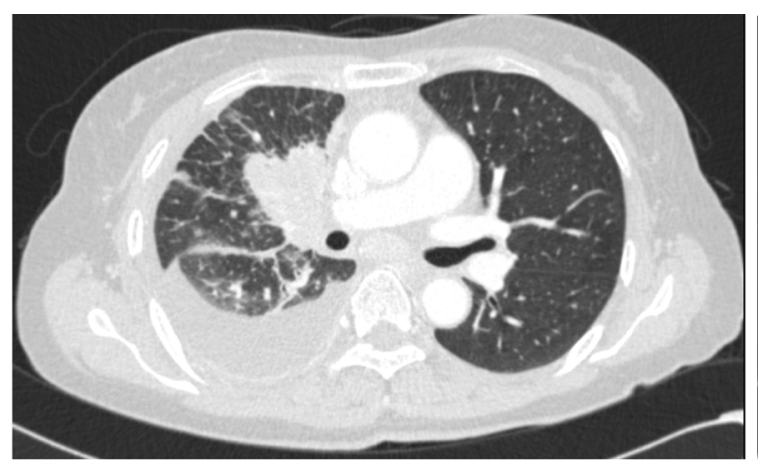

Symptomatic disease progression during erlotinib $150 \mathrm{mg} /$ day as the first line treatment

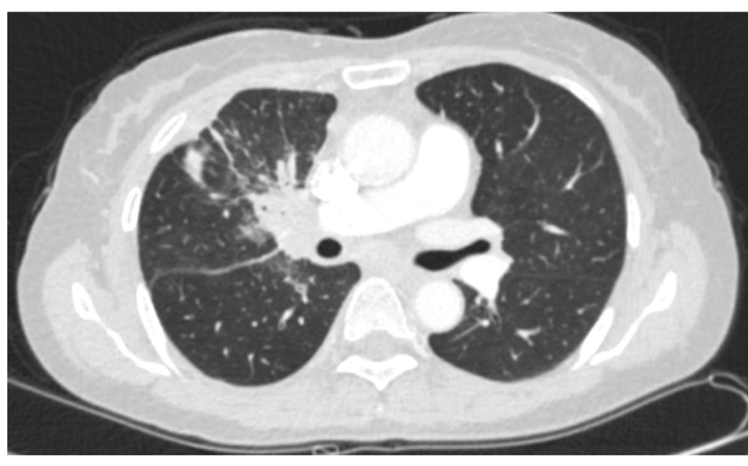

Clinical and radiological response to HM61713 800 $\mathrm{mg} /$ day

22-day delay for confirmatory tissue genotyping

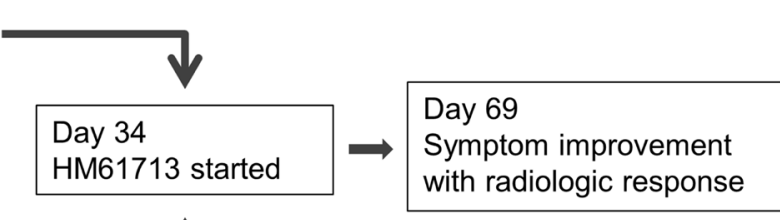

\begin{tabular}{|l|l|}
\hline $\begin{array}{l}\text { Day } 0 \\
\text { Lung biopsy ordered }\end{array} \rightarrow \begin{array}{l}\text { Tissue EGFR T790M } \\
\text { negative test results } \\
\text { after 23 days }\end{array}$ \\
\hline
\end{tabular}
Plasma EGFR T790M positive test results after 48 hours

Day 0
Liquid biopsy ordered $\longrightarrow \begin{aligned} & \text { positive test results } \\ & \text { after } 48 \text { hours }\end{aligned}$

Figure 4: A patient with metastatic NSCLC with acquired resistance to erlotinib who showed a partial response to third-generation TKI. 
enrolled in a prospective trial of first-generation EGFR-TKI (gefitinib or erlotinib) at Yonsei Cancer Center in Korea. Activating EGFR mutations were defined as mutations known to be associated with EGFR-TKI sensitivity, including E19del and L858R. Patients with available archival tissue and those with measurable lesions at baseline were enrolled. Baseline tissue and blood plasma samples were collected before EGFR-TKI administration. Serial plasma sampling and tissue or plasma sampling at the time of progression were optional in our trial. This study was approved by the Institutional Review Board and the ethics committee of Yonsei Cancer Center. All patients provided written informed consent for study participation and genetic analysis.

\section{Study objectives}

The primary objective was to assess the diagnostic utility of plasma sampling using matched tissue and plasma samples. Sensitivity, specificity, PPV, NPV, and concordance rate were analyzed in comparison to specific tissue EGFR mutation status. Secondary objectives included assessment of the prognostic and predictive value of plasma $E G F R$ mutations at baseline and serial sampling, monitoring acquired resistance, and comparison between tissue and plasma samples upon disease progression.

\section{Treatment and evaluation of response}

Patients received erlotinib at $150 \mathrm{mg} / \mathrm{d}$ or gefitinib at $250 \mathrm{mg} / \mathrm{d}$. Evaluation of response by computed tomography scans was performed four weeks after the baseline study, and then every eight weeks thereafter according to the RECIST 1.1 guidelines. Serial sampling was performed at the time of response evaluation. Treatment was continued until disease progression, intolerable toxicity, or withdrawal of consent.

\section{Data collection}

Medical records and radiologic images of all patients were collected to evaluate demographic and clinicopathologic parameters, tumor response, PFS, and OS. Never smokers were defined as those with a lifetime smoking dose of less than 100 cigarettes. PFS was measured from the first day of treatment with EGFR-TKI to tumor progression or death. OS was measured from the first date of treatment with EGFR-TKI until the date of death. Patients were censored at the last visiting if alive and progression-free. Sensitivity, specificity, PPV, NPV, and concordance rate were calculated for E19del, L858R, and T790M mutations as described in Supplementary Table 3.

\section{DNA extraction}

Tumor DNA was extracted using the Maxwell R 16 FFPE purification kit (Promega, Mannheim, Germany) and ctDNA was extracted from $1 \mathrm{~mL}$ of plasma using the QIAamp MinElute Virus Spin kit (QIAGEN, Hilden, Germany) according to the manufacturers' protocols.

\section{EGFR mutation analysis for tissue}

We used the PNAClamp ${ }^{\mathrm{TM}} E G F R$ Mutation Detection kit (PANAGENE Inc., Daejeon, Korea) to detect EGFR mutations by real-time PCR. All reactions were performed in $20 \mu \mathrm{l}$ volumes containing template DNA, primer and PNA probe sets, and fluorescence PCR master mix. All reagents were included in the kit. Real-time PCR reactions of PNA-mediated clamping PCR were performed using a CFX 96 system (Bio-Rad, Hercules, CA, USA). PCR cycling conditions were a $5 \mathrm{~min}$ hold at $94^{\circ} \mathrm{C}$, followed by 40 cycles of $94^{\circ} \mathrm{C}$ for $30 \mathrm{sec}, 70^{\circ} \mathrm{C}$ for $20 \mathrm{sec}, 63^{\circ} \mathrm{C}$ for $30 \mathrm{sec}$, and $72^{\circ} \mathrm{C}$ for $30 \mathrm{sec}$. The lowest mutation allele frequency for the E19del, L858R, and T790M mutations measured by the PNAClamp ${ }^{\mathrm{TM}} E G F R$ was set as $1.0 \%$, corresponding to one mutated copy in 100 copies of wild type DNA (Supplementary Figure 1).

\section{EGFR mutation analysis for plasma}

The PANAMutyper ${ }^{\mathrm{TM}} E G F R$ kit was used for mutation detection. The PANAMutyper ${ }^{\mathrm{TM}} E G F R$ kit is a newly developed mutation detection kit designed to detect 47 different EGFR variants in exons 18-21 with high sensitivity using PNA clamping-assisted fluorescence melting curve analysis for mutation detection and genotyping. All reactions were performed in a total volume of $25 \mu \mathrm{l}$ that contained $10-25 \mathrm{ng}$ of DNA templates, primer and PNA probe sets, and PCR master mix. All reagents used were included with the kit. PCR was performed under the following conditions: $50^{\circ} \mathrm{C}$ for $2 \mathrm{~min}$ and $95^{\circ} \mathrm{C}$ for $15 \mathrm{~min}$ as two holding periods; 15 cycles of $95^{\circ} \mathrm{C}$ for $30 \mathrm{sec}, 70^{\circ} \mathrm{C}$ for $20 \mathrm{sec}, 63^{\circ} \mathrm{C}$ for $60 \mathrm{sec} ; 35$ cycles of $95^{\circ} \mathrm{C}$ for $10 \mathrm{sec}, 53^{\circ} \mathrm{C}$ for $20 \mathrm{sec}$, $73^{\circ} \mathrm{C}$ for $20 \mathrm{sec}$; and a melting curve step (from $35^{\circ} \mathrm{C}$ to $75^{\circ} \mathrm{C}$ with gradual increment for $0.5^{\circ} \mathrm{C}$ for $3 \mathrm{sec}$ ). Fluorescence was measured on all four channels (FAM, ROX, Cy5, and HEX). Melting peaks were derived from the melting curve data. Mutations were detected by the melting temperature of each tube for each fluorescent dye as shown in Supplementary Table 4.

The total amount of plasma volume required for assay was $1 \mathrm{~mL}$ and all samples were successfully genotyped. The median amounts of amplifiable DNA extracted from plasma for E19del, L858R, and T790M were 711.6 (range, 0-8707.3), 206.1 (range, 0-1721.7), and 68.5 (range, $0-1262.9$ ) copies/mL, respectively. The lowest mutation allele frequency for the E19del, L858R, and T790M mutations measured by the PANAMutyper ${ }^{\mathrm{TM}}$ was set as $0.01 \%$, corresponding to one mutated copy in 10,000 copies of wild type DNA (Supplementary Figure 2). This cut-off value yielded 100\% specificity 
when plasma derived from 10 healthy volunteers (ZenBio Inc., Durham, NC, USA) and normal genomic DNA (Horizon Dx Inc., Cambridge, UK) was tested (Supplementary Figure 3). All results were available within three hours with this ready-to-use kit.

\section{Statistical analysis}

Fisher's exact test and Wilcoxon rank-sum test were used for categorical and continuous variables. Survival distribution was estimated by the Kaplan-Meier method, and the Cox proportional hazards model was used to analyze the effect of specified risk factors on survival. Results were considered statistically significant at a $P$ value $<0.05$. All analyses were performed using statistical software package SPSS for Windows software, version 22.0 (SPSS Inc., Chicago, IL, USA).

\section{ACKNOWLEDGMENTS}

The authors would like to thank Dong-Su Jang, a medical illustrator in the medical research support section of Yonsei University College of Medicine, Seoul, Korea, for assistance with the illustrations and Su Kyoung Park, a medical record administrator in the analysis division of the medical record team at this institution, for assistance with data management.

\section{CONFLICTS OF INTEREST}

The authors declare no conflicts of interest.

\section{GRANT SUPPORT}

This work was supported by a new faculty research seed money grant of Yonsei University College of Medicine for 2016-32-0014, H.R. Kim, and a faculty research grant of Yonsei University College of Medicine for 6-2016-0104, H.R. Kim.

\section{REFERENCES}

1. Mok TS, Wu YL, Thongprasert S, Yang CH, Chu DT, Saijo N, Sunpaweravong P, Han B, Margono B, Ichinose Y, Nishiwaki Y, Ohe Y, Yang JJ, et al. Gefitinib or carboplatinpaclitaxel in pulmonary adenocarcinoma. N Engl J Med. 2009; 361:947-57.

2. Maemondo M, Inoue A, Kobayashi K, Sugawara S, Oizumi S, Isobe H, Gemma A, Harada M, Yoshizawa H, Kinoshita I, Fujita Y, Okinaga S, Hirano H, et al, and North-East Japan Study Group. Gefitinib or chemotherapy for non-small-cell lung cancer with mutated EGFR. N Engl J Med. 2010; $362: 2380-88$.

3. Mitsudomi T, Morita S, Yatabe Y, Negoro S, Okamoto I, Tsurutani J, Seto T, Satouchi M, Tada H, Hirashima T,
Asami K, Katakami N, Takada M, et al, and West Japan Oncology Group. Gefitinib versus cisplatin plus docetaxel in patients with non-small-cell lung cancer harbouring mutations of the epidermal growth factor receptor (WJTOG3405): an open label, randomised phase 3 trial. Lancet Oncol. 2010; 11:121-28.

4. Rosell R, Carcereny E, Gervais R, Vergnenegre A, Massuti B, Felip E, Palmero R, Garcia-Gomez R, Pallares C, Sanchez JM, Porta R, Cobo M, Garrido P, et al, and Spanish Lung Cancer Group in collaboration with Groupe Français de Pneumo-Cancérologie and Associazione Italiana Oncologia Toracica. Erlotinib versus standard chemotherapy as first-line treatment for European patients with advanced EGFR mutation-positive non-small-cell lung cancer (EURTAC): a multicentre, open-label, randomised phase 3 trial. Lancet Oncol. 2012; 13:239-46.

5. Engelman JA, Zejnullahu K, Mitsudomi T, Song Y, Hyland C, Park JO, Lindeman N, Gale CM, Zhao X, Christensen J, Kosaka T, Holmes AJ, Rogers AM, et al. MET amplification leads to gefitinib resistance in lung cancer by activating ERBB3 signaling. Science. 2007; 316:1039-43.

6. Takezawa K, Pirazzoli V, Arcila ME, Nebhan CA, Song X, de Stanchina E, Ohashi K, Janjigian YY, Spitzler PJ, Melnick MA, Riely GJ, Kris MG, Miller VA, et al. HER2 amplification: a potential mechanism of acquired resistance to EGFR inhibition in EGFR-mutant lung cancers that lack the second-site EGFRT790M mutation. Cancer Discov. 2012; 2:922-33.

7. Byers LA, Diao L, Wang J, Saintigny P, Girard L, Peyton M, Shen L, Fan Y, Giri U, Tumula PK, Nilsson MB, Gudikote $\mathrm{J}$, Tran $\mathrm{H}$, et al. An epithelial-mesenchymal transition gene signature predicts resistance to EGFR and PI3K inhibitors and identifies Axl as a therapeutic target for overcoming EGFR inhibitor resistance. Clin Cancer Res. 2013; 19:279-90.

8. Yu HA, Arcila ME, Rekhtman N, Sima CS, Zakowski MF, Pao W, Kris MG, Miller VA, Ladanyi M, Riely GJ. Analysis of tumor specimens at the time of acquired resistance to EGFR-TKI therapy in 155 patients with EGFR-mutant lung cancers. Clin Cancer Res. 2013; 19:2240-47.

9. Jänne PA, Yang JC, Kim DW, Planchard D, Ohe Y, Ramalingam SS, Ahn MJ, Kim SW, Su WC, Horn L, Haggstrom D, Felip E, Kim JH, et al. AZD9291 in EGFR inhibitor-resistant non-small-cell lung cancer. N Engl J Med. 2015; 372:1689-99.

10. Diaz LA Jr, Bardelli A. Liquid biopsies: genotyping circulating tumor DNA. J Clin Oncol. 2014; 32:579-86.

11. Overman MJ, Modak J, Kopetz S, Murthy R, Yao JC, Hicks ME, Abbruzzese JL, Tam AL. Use of research biopsies in clinical trials: are risks and benefits adequately discussed? J Clin Oncol. 2013; 31:17-22.

12. Gerlinger M, Rowan AJ, Horswell S, Math M, Larkin J, Endesfelder D, Gronroos E, Martinez P, Matthews N, Stewart A, Tarpey P, Varela I, Phillimore B, et al. Intratumor heterogeneity and branched evolution revealed by multiregion sequencing. N Engl J Med. 2012; 366:883-92. 
13. Newman AM, Bratman SV, To J, Wynne JF, Eclov NC, Modlin LA, Liu CL, Neal JW, Wakelee HA, Merritt RE, Shrager JB, Loo BW Jr, Alizadeh AA, Diehn M. An ultrasensitive method for quantitating circulating tumor DNA with broad patient coverage. Nat Med. 2014; 20:548-54.

14. Tabernero J, Lenz HJ, Siena S, Sobrero A, Falcone A, Ychou M, Humblet Y, Bouché O, Mineur L, Barone C, Adenis A, Yoshino T, Goldberg RM, et al. Analysis of circulating DNA and protein biomarkers to predict the clinical activity of regorafenib and assess prognosis in patients with metastatic colorectal cancer: a retrospective, exploratory analysis of the CORRECT trial. Lancet Oncol. 2015; 16:937-48.

15. Dawson SJ, Tsui DW, Murtaza M, Biggs H, Rueda OM, Chin SF, Dunning MJ, Gale D, Forshew T, MahlerAraujo B, Rajan S, Humphray S, Becq J, et al. Analysis of circulating tumor DNA to monitor metastatic breast cancer. N Engl J Med. 2013; 368:1199-209.

16. Luo J, Shen L, Zheng D. Diagnostic value of circulating free DNA for the detection of EGFR mutation status in NSCLC: a systematic review and meta-analysis. Sci Rep. 2014; 4:6269.

17. Qiu M, Wang J, Xu Y, Ding X, Li M, Jiang F, Xu L, Yin R. Circulating tumor DNA is effective for the detection of EGFR mutation in non-small cell lung cancer: a metaanalysis. Cancer Epidemiol Biomarkers Prev. 2015; 24:206-12.

18. Sundaresan TK, Sequist LV, Heymach JV, Riely GJ, Janne PA, Koch WH, Sullivan JP, Fox DB, Maher R, Muzikansky A, Webb A, Tran HT, Giri U, et al. Detection of T790M, the Acquired Resistance EGFR Mutation, by Tumor Biopsy versus Noninvasive Blood-Based Analyses. Clin Cancer Res. 2016; 22:1103-10. https://doi.org/10.1158/1078-0432. ccr-15-1031.

19. Piotrowska Z, Niederst MJ, Karlovich CA, Wakelee HA, Neal JW, Mino-Kenudson M, Fulton L, Hata AN, Lockerman EL, Kalsy A, Digumarthy S, Muzikansky A, Raponi M, et al. Heterogeneity Underlies the Emergence of EGFRT790 Wild-Type Clones Following Treatment of T790M-Positive Cancers with a Third-Generation EGFR Inhibitor. Cancer Discov. 2015; 5:713-22.

20. Spellman PT, Gray JW. Detecting cancer by monitoring circulating tumor DNA. Nat Med. 2014; 20:474-75.

21. Han HS, Lim SN, An JY, Lee KM, Choe KH, Lee KH, Kim ST, Son SM, Choi SY, Lee HC, Lee OJ. Detection of EGFR mutation status in lung adenocarcinoma specimens with different proportions of tumor cells using two methods of differential sensitivity. J Thorac Oncol. 2012; 7:355-64.

22. Won JK, Keam B, Koh J, Cho HJ, Jeon YK, Kim TM, Lee SH, Lee DS, Kim DW, Chung DH. Concomitant ALK translocation and EGFR mutation in lung cancer: a comparison of direct sequencing and sensitive assays and the impact on responsiveness to tyrosine kinase inhibitor. Ann Oncol. 2015; 26:348-54.
23. Kim HR, Cho BC, Shim HS, Lim SM, Kim SK, Chang J, Kim DJ, Kim JH. Prediction for response duration to epidermal growth factor receptor-tyrosine kinase inhibitors in EGFR mutated never smoker lung adenocarcinoma. Lung Cancer. 2014; 83:374-82.

24. Huang WL, Chen YL, Yang SC, Ho CL, Wei F, Wong DT, $\mathrm{Su}$ WC, Lin CC. Liquid biopsy genotyping in lung cancer: ready for clinical utility? Oncotarget. 2017; 8:18590-18608. https://doi.org/10.18632/oncotarget.14613.

25. Kim HR, Lee SY, Hyun DS, Lee MK, Lee HK, Choi CM, Yang SH, Kim YC, Lee YC, Kim SY, Jang SH, Lee JC, Lee KY. Detection of EGFR mutations in circulating free DNA by PNA-mediated PCR clamping. J Exp Clin Cancer Res. 2013; 32:50.

26. Han JY, Choi JJ, Kim JY, Han YL, Lee GK. PNA clampingassisted fluorescence melting curve analysis for detecting EGFR and KRAS mutations in the circulating tumor DNA of patients with advanced non-small cell lung cancer. BMC Cancer. 2016; 16:627.

27. Douillard JY, Ostoros G, Cobo M, Ciuleanu T, Cole R, McWalter G, Walker J, Dearden S, Webster A, Milenkova T, McCormack R. Gefitinib treatment in EGFR mutated caucasian NSCLC: circulating-free tumor DNA as a surrogate for determination of EGFR status. J Thorac Oncol. 2014; 9:1345-53.

28. Mok T, Wu YL, Lee JS, Yu CJ, Sriuranpong V, SandovalTan J, Ladrera G, Thongprasert S, Srimuninnimit V, Liao M, Zhu Y, Zhou C, Fuerte F, et al. Detection and Dynamic Changes of EGFR Mutations from Circulating Tumor DNA as a Predictor of Survival Outcomes in NSCLC Patients Treated with First-line Intercalated Erlotinib and Chemotherapy. Clin Cancer Res. 2015; 21:3196-203.

29. Paweletz CP, Sacher AG, Raymond CK, Alden RS, O'Connell A, Mach SL, Kuang Y, Gandhi L, Kirschmeier P, English JM, Lim LP, Jänne PA, Oxnard GR. BiasCorrected Targeted Next-Generation Sequencing for Rapid, Multiplexed Detection of Actionable Alterations in Cell-Free DNA from Advanced Lung Cancer Patients. Clin Cancer Res. 2016; 22:915-22.

30. Lee JY, Qing X, Xiumin W, Yali B, Chi S, Bak SH, Lee HY, Sun JM, Lee SH, Ahn JS, Cho EK, Kim DW, Kim HR, et al. Longitudinal monitoring of EGFR mutations in plasma predicts outcomes of NSCLC patients treated with EGFR TKIs: Korean Lung Cancer Consortium (KLCC-12-02). Oncotarget. 2016; 7:6984-93. https://doi.org/10.18632/ oncotarget.6874.

31. Ettinger DS, Wood DE, Akerley W, Bazhenova LA, Borghaei H, Camidge DR, Cheney RT, Chirieac LR, D'Amico TA, Demmy TL, Dilling TJ, Dobelbower MC, Govindan R, et al, and National comprehensive cancer network. Non-Small Cell Lung Cancer, Version 6.2015. J Natl Compr Canc Netw. 2015; 13:515-24.

32. Karlovich C, Goldman JW, Sun JM, Mann E, Sequist LV, Konopa K, Wen W, Angenendt P, Horn L, Spigel D, Soria 
JC, Solomon B, Camidge DR, et al. Assessment of EGFR Mutation Status in Matched Plasma and Tumor Tissue of NSCLC Patients from a Phase I Study of Rociletinib (CO1686). Clin Cancer Res. 2016; 22:2386-95.

33. Graziano P, de Marinis F, Gori B, Gasbarra R, Migliorino R, De Santis S, Pelosi G, Leone A. EGFR-Driven Behavior and Intrapatient T790M Mutation Heterogeneity of NonSmall-Cell Carcinoma With Squamous Histology. J Clin Oncol. 2015; 33:e115-18.
34. Hata A, Katakami N, Yoshioka H, Kaji R, Masago K, Fujita S, Imai Y, Nishiyama A, Ishida T, Nishimura Y, Yatabe Y. Spatiotemporal T790M Heterogeneity in Individual Patients with EGFR-Mutant Non-Small-Cell Lung Cancer after Acquired Resistance to EGFR-TKI. J Thorac Oncol. 2015; 10:1553-59. 